\title{
Influência dos valores organizacionais sobre estilos de gerenciamento em empresas de pequeno porte ${ }^{1}$
}

\author{
Eliana Elisabete Moreira Gosendo ${ }^{2}$ \\ Centro Universitário UNIEURO, Brasília-DF, Brasil \\ Cláudio Vaz Torres \\ Universidade de Brasília, Brasília-DF, Brasil
}

\begin{abstract}
Resumo: No cenário das pequenas empresas são escassas as pesquisas realizadas pela Psicologia Social e do Trabalho, bem como pouco se têm estudado populações com baixa escolaridade. Os objetivos desta pesquisa foram identificar a hierarquia dos valores organizacionais e os estilos de gerenciamento e investigar a influência dos valores organizacionais nos estilos de gerenciamento. A amostra foi composta de empregados de 30 empresas. Na coleta de dados, adotou-se método adaptado para pessoas com baixa escolaridade. Os resultados apontaram o valor organizacional Domínio e o estilo de gerenciamento Tarefa como os mais percebidos pelos empregados. Os valores Autonomia e Bem-Estar aparecem como os melhores preditores para o estilo Relacionamento. O valor Conformidade é o único preditor do estilo Tarefa e o valor Autonomia é o melhor preditor do estilo Situação.
\end{abstract}

Palavras-chave: valores, liderança, escolaridade.

\section{The influence of organizational values on the management styles of small firms}

\begin{abstract}
There is a scarcity of studies addressing Psychology and Social Work in the context of small firms and few addressing populations with low educational level. This study aimed to identify the hierarchy of organizational values and management styles and to investigate the influence of organizational values on management styles. The sample was composed of employees from 30 firms. A method adapted to individuals with low educational level was used in data collection. The results indicate that the organizational value "Control" and management style "Task-oriented" were the most perceived by employees. The values "Autonomy" and "Well-Being" were the best predictors of the "Relationship-oriented" management style. The value "Conformity" is the only predictor of the management style "Task-oriented" and the value "Autonomy" is the best predictor of the management style "Situational".
\end{abstract}

Keywords: values, leadership, educational status.

\section{Influencia de los valores organizacionais en los estilos de gerencia de las empresas de pequeño porte}

\begin{abstract}
Resumen: En la escena de las compañías pequeñas, la investigación llevadas a través para la psicología social y del trabajo es escasa, tan bien como pequeño ha estudiado a poblaciones con bajo escolaridade. Los objetivos de actual investigación fueron identificar a la jerarquía de los valores organizacionais y los estilos de gerencia y investigar la influencia de los valores en los estilos de gerencia. La muestra fue compuesta de empleados de 20 compañías. En la recogida de datos, el método del uso adoptado se adaptó para la gente con el escolaridade bajo. Los resultados mostraron el valor organizacional Dominio y el estilo de gerencia Tarea como los más percibidos por la mayoría de los empleados. Los valores Autonomía y Bienestar surgieron como los mejores preditores para la gerencia Relación. El valor Conformidad es el único preditor del estilo Tarea y el valor Autonomía es preditor óptimo del estilo Situación.
\end{abstract}

Palabras clave: valores, liderazgo, escolaridad.

O impacto da cultura no comportamento humano tem sido objeto de estudos tanto nas ciências do comportamento quanto nas ciências sociais (Tamayo \& Porto, 2005). Existe uma gama considerável de pesquisadores se dedicando ao

1 Apoio: CAPES. Este artigo é derivado da Dissertação de Mestrado defendida pela primeira autora, sob a orientação do segundo, junto ao Programa de Pós-graduação em Psicologia Social e do Trabalho do Instituto de Psicologia da Universidade de Brasília, Brasília, DF. Esse texto foi revisado seguindo o Acordo Ortográfico da Língua Portuguesa (1990), em vigor a partir de $1^{\circ}$ de janeiro de 2009.

2 Endereço para correspondência:

Profa. Dra. Eliana Elisabete Moreira Gosendo. Centro Universitário UNIEURO. Mestrado em Administração. Setor de Embaixadas e Clubes Sul, Av. das Nações, trecho 0, conjunto 5. CEP 70.200-001. Brasília-DF, Brasil.E-mail: gosendo@gmail.com. estudo da influência dos valores culturais, tentando identificar características de comportamento das pessoas de culturas diferentes frente a determinadas situações.

Entretanto, ainda é pequena a quantidade de estudos abrangendo os valores organizacionais. De acordo com Silva (2007), apesar das diferentes conceituações e medidas sobre o construto, podem-se assinalar alguns elementos recorrentes nas pesquisas sobre o tema. Esses elementos relacionam-se com alcance de objetivos ou metas organizacionais e com atendimentos às necessidades dos membros organizacionais.

É com base no pressuposto de que os valores exercem papel fundamental na vida organizacional, moldando e direcionando suas metas e estratégias de ação, que este estudo investiga a relação existente entre os valores organizacionais 
e os estilos de gerenciamento praticados em micro e pequenas empresas de vestuário. Em termos mais gerais, o estudo propõe que as organizações não são apenas influenciadas por seus ambientes, mas também por seus membros.

Contrapondo-se ao modelo Fordista baseado na grande empresa, ganham força, no Brasil, no final da década de 90 , as formas cooperativas de trabalho focadas no desenvolvimento local sustentável (Cocco, Urani, Galvão, \& Silva, 2002). Essas formas cooperativas de trabalho tornam-se de fundamental importância para o enfrentamento dos desafios que se apresentam na era globalizada ou era do conhecimento, exigindo a incorporação de novas tendências às políticas de promoção do desenvolvimento tecnológico e industrial.

O Sistema Brasileiro de Apoio às Micro e Pequenas Empresas - SEBRAE volta-se, então, para uma abordagem de perspectiva territorial, a partir da realização de seminários, no período de 2001 a 2002, com o objetivo de buscar novos modelos que pudessem promover o aumento de emprego e de renda em nosso país (SEBRAE, 2004). Assim, os Arranjos Produtivos Locais - APL foram incluídos nas prioridades da instituição, caracterizando-se como um instrumento estratégico de intervenção nos micro e pequenos empreendimentos.

A partir do Termo de Referência para Mobilização de Arranjos Produtivos Locais, versão 4.1, elaborada em 2003, o Sistema SEBRAE (2004) especifica sua forma de atuação e define o Arranjo Produtivo Local - APL - como:

Aglomerações de empresas, localizadas em um mesmo território, que apresentam especialização produtiva e mantêm algum vínculo de articulação, interação, cooperação e aprendizagem entre si e com outros atores sociais, tais como: governo, associações empresariais, instituições de crédito, ensino e pesquisa (p. 4).

É uma abordagem centrada no desenvolvimento local, onde se estabelecem relações de confiança e de trocas entre os diversos atores, articulações entre as empresas e entre as empresas e outros agentes locais, aprendendo coletivamente, de modo a fortalecer as micro e pequenas empresas, públicoalvo do Sistema SEBRAE.

Dentro do cenário das micro e pequenas empresas, é destacado o aspecto chamado de "governança" nesse processo de desenvolvimento sustentável local, por meio do modelo do Arranjo Produtivo Local - APL. Para o Sistema SEBRAE, governança refere-se aos diversos modos de liderança, envolvendo diferentes agentes (governo, empresas, cidadãos e trabalhadores, organizações não-governamentais, entre outros) e diversas atividades produtivas e processos de geração, disseminação e aplicação do conhecimento (Termo de Referência ..., 2003). Esses diferentes modos de liderança constituem nas empresas os estilos de gerenciamento daqueles que exercem influência sobre os empregados da organização. Assim, o processo de gerenciamento surge assumindo papel estratégico na implementação e manutenção da cultura organizacional necessária aos APL.

Embora o fenômeno da liderança tenha sido vastamente estudado na área do comportamento organizacional, ele não tem sido muito investigado em relação aos valores organizacionais.

As micro e pequenas empresas em geral, especificamente as que participaram deste estudo, guardam características bastante peculiares e diversas do mundo das grandes organizações de trabalho, onde têm se concentrado a maioria das pesquisas, especialmente na Psicologia Social e do Trabalho. É importante, pois, que seja ressaltada a importância da realização desta pesquisa e de seus resultados ao contribuir para melhor compreensão da dinâmica dessas pequenas organizações, bem como por estudar a percepção de pessoas com baixa escolaridade, utilizando-se uma forma específica de coleta de dados, adaptada de Borges e Pinheiro (2002).

A presente pesquisa estudou o Arranjo Produtivo Local de Vestuário por ser considerado, no período, o segmento mais bem estruturado e desenvolvido no Distrito Federal e seu entorno, dentre aqueles assistidos pelo SEBRAE/DF. À época da pesquisa, final de 2004, o APL de vestuário era formado por 110 micro e pequenas empresas localizadas no Distrito Federal e seu entorno, de acordo com dados fornecidos pelo Sindicato das Indústrias de Vestuário - SINDIVESTE.

\section{Desenvolvimento Conceitual}

\section{Valores Organizacionais}

As organizações, além de reagirem às exigências internas, advindas das necessidades e motivações de seus membros, precisam também responder às exigências externas, formadas pelas necessidades e motivações de seus clientes e parceiros de negócio. Assim, ao buscarem soluções para atender a essas necessidades, as empresas definem as suas metas, que representam os valores organizacionais.

A partir das necessidades universais das organizações e com base na abordagem cultural dos valores apresentada por Schwartz (1999), postulam-se três dimensões bipolares que representam as alternativas de resposta das organizações às suas necessidades básicas (Tamayo, 1996):

1. Autonomia versus Conservação - decorre das soluções dadas à necessidade de resolver o conflito existente na relação entre o indivíduo e a organização. Empresas com valor Autonomia são aquelas que creem na capacidade de realização dos seus empregados de forma autônoma, perseguindo seus próprios interesses e metas em harmonia com as metas e normas organizacionais. Em contraposição a essa dimensão, encontramos as empresas que valorizam os interesses do grupo, sendo o interesse do indivíduo considerado como igual ao do grupo. Elas enfatizam a manutenção do status $q u o$, impedindo comportamentos que possam desestabilizar a vida organizacional, que venham a infringir suas normas e tradições.

2. Hierarquia versus Estrutura Igualitária - surge a partir das soluções dadas ao problema da estruturação organizacional, quando as empresas precisam definir suas funções e a 
relação entre suas unidades e entre seus membros. Teremos, então, as organizações que priorizam a hierarquia como forma de garantir o comprometimento dos empregados, a legitimidade na distribuição dos recursos e dos papéis sociais na organização. No outro pólo dessa dimensão, temos as organizações que optam pela estrutura igualitária, preocupadas com o bem-estar de todos na organização. Nessas organizações, são poucos os níveis hierárquicos e o gerenciamento se faz por consenso.

3. Harmonia versus Domínio - a organização, para estar inserida no mundo dos negócios, precisa definir o tipo de relacionamento que irá estabelecer com o meio físico e social. A partir daí, duas alternativas opostas se apresentam. Na primeira estão as organizações que se voltam para os valores de harmonia, buscando o desenvolvimento e o sucesso por meio de interações harmoniosas e equilibradas. Na segunda alternativa encontramos as organizações em que predominam os valores de domínio, de busca de sucesso, impondo sua imagem e seus produtos.

Tamayo e Gondim (1996) definem os valores organizacionais como "princípios ou crenças, organizados hierarquicamente, relativos a metas e a comportamentos organizacionais desejáveis que orientam a vida da empresa e estão a serviço de interesses individuais, coletivos ou mistos" (p. 63).

De outra forma, Kabanof e Daly (2002) entendem que os valores organizacionais são aqueles que as pessoas, e principalmente a alta direção, empossam ou expressam em nome do coletivo. Esses valores estão presentes em documentos, discursos e comunicações.

Parece-nos que as duas abordagens são complementares, pois a identificação dos valores compartilhados pelo grupo e empossados pela organização e alta direção em documentos, possibilita uma maior compreensão do ambiente organizacional.

Os valores organizacionais compartilhados pelo grupo são investigados no nível individual, ou seja, por meio das percepções agregadas dos membros organizacionais. Apesar disso, os valores organizacionais não devem ser confundidos com os valores pessoais, que podem ser compatíveis ou não em relação aos valores da organização. Contudo, tanto os valores pessoais quanto os valores organizacionais compartilham metas universais que expressam satisfação de exigências básicas do ser humano. Nesse sentido, o estudo dos valores organizacionais pode ter suas origens nos valores pessoais.

De acordo com Koslowsky e Stashevsky (2005), os meios que a organização utiliza para obter a confiança dos empregados podem ser vistos como decorrentes dos valores organizacionais. Assim, caso os empregados avaliem que não têm sido tratados com honestidade, podem desenvolver atitude negativa, que influenciará em seus desempenhos e rotatividade de pessoal.

Com base nesse pressuposto, Oliveira e Tamayo (2004) construíram o Inventário de Perfis de Valores Organizacionais
- IPVO, no qual os tipos motivacionais foram definidos a partir dos valores pessoais e feita a transposição para as organizações. O objetivo foi analisar a relação dos valores organizacionais com os valores pessoais, com base no conteúdo motivacional dos valores pessoais. Neste estudo, esse instrumento foi utilizado para avaliar a percepção dos empregados quanto aos valores predominantes em suas organizações.

\section{Liderança organizacional}

Poucos estudos sobre liderança têm investigado o impacto dos valores culturais sobre essa variável. Claramente, nós ainda não temos uma resposta precisa a respeito de como a cultura pode influenciar a efetividade de um líder, embora possamos considerar que os processos de liderança refletem essas diferenças culturais. Por exemplo, Dorfman (1996) notou que as recompensas individuais, característica das organizações norte-americanas, não podem ser consideradas como a norma em culturas mais coletivistas, como aquelas encontradas em países latinos. Seguindo a mesma linha de pensamento, não seria razoável a mera "exportação" de abordagens participativas ou de liderança democrática para culturas onde existe a percepção da forte diferenciação de poder entre subordinados e líder.

$\mathrm{O}$ fato é que nós ainda sabemos pouco sobre o impacto da cultura e dos valores nos processos de liderança (Smith e cols., 1994; Torres, 1999). Este artigo pretende fazer uma breve discussão sobre o estudo de liderança, usando como modelo a abordagem de Hersey e Blanchard (1974), operacionalizada por Melo (2001). Sugere-se que o protótipo do "líder ideal" varia dependendo dos valores organizacionais endossados, e que o conceito de valores pode ser usado para entender como esse "líder ideal" é concebido em diferentes lugares. Os valores podem influenciar não só o estilo de liderança que é aceito em diferentes organizações, mas também a efetividade de diferentes comportamentos de liderança.

Nas organizações, a liderança assume o significado e as características de gerenciamento, passando os termos líder e gerente a serem utilizados como sinônimos. Segundo Torres (1999), alguns estudiosos do assunto consideram que o gerenciamento envolve atividades que produzem consistência, enquanto liderança diz respeito ao processo de influência. $\mathrm{O}$ autor considera que quando o gerente orienta o grupo para realização dos objetivos e metas organizacionais, pode ser considerado um líder. Portanto, neste estudo, liderança e gerenciamento foram utilizados com um mesmo significado, por se considerar a liderança como um dos aspectos do gerenciamento e da atuação eficaz de um gerente, ou seja, aquele que exerce liderança com o intuito de direcionar as ações de seus subordinados.

A liderança não ocorre no isolamento, ela se estabelece através da relação entre pessoas por meio da influência e do poder que são distribuídos de maneira desigual numa base legítima (contratual ou consensual). Assim, a liderança resulta da relação assimétrica de poder, ou, mais especificamente, da influência que uma pessoa exerce sobre outras pessoas. De 
acordo com Dorfman (1996), não existe liderança sem seguidores; a liderança irá ocorrer se as pessoas aceitarem seguir o líder, legitimando-o na situação específica. A liderança, nas abordagens contemporâneas, é vista como um atributo que decorre da situação. Portanto, a pessoa não nasce líder, são os seguidores que atribuem a ela essa característica.

Liu, Lepak, Takeuchi e Sims Jr.(2003) afirmam que certos estilos de liderança são mais suscetíveis de serem eficazes em determinados regimes de emprego do que em outros. Atualmente, as empresas estão utilizando, cada vez mais, trabalhadores terceirizados para realizarem tarefas específicas, que não são de valor estratégico para a organização. Assim, a natureza do contrato de trabalho sugere um estilo de gerenciamento que possa, essencialmente, assegurar o cumprimento dos termos contratuais por meio, por exemplo, de uma liderança diretiva, em vez de se buscar o comprometimento e satisfazer as expectativas dos empregados.

Além dos aspectos do contexto do trabalho, os padrões de comportamento dos líderes sofrem também influência dos aspectos culturais. De acordo com Torres (1999), os padrões culturais podem influenciar o estilo de liderança que é aceito em vários países e também a efetividade do comportamento do líder. As filosofias e as práticas gerenciais têm se apresentado de formas distintas em diferentes organizações através dos países, embora se possam identificar elementos comuns do comportamento gerencial nas organizações de uma mesma cultura (Bass, 1990).

Portanto, para compreendermos o fenômeno da liderança, devem ser consideradas as características do líder, os seus comportamentos e as condições da situação. Seguindo essa concepção, utilizou-se nesta pesquisa três estilos gerenciais que vêm, de acordo com Melo (2001), permeando a grande maioria dos estudos sobre liderança: gerenciamento voltado para o relacionamento, gerenciamento voltado para a tarefa e gerenciamento voltado para a situação. Foi considerada a abordagem de Hersey e Blanchard (1974) para o estilo voltado para a situação.

A partir do contexto apresentado, derivam-se os seguintes objetivos deste estudo: (a) identificar a hierarquia dos valores organizacionais percebidos pelos empregados pertencentes às empresas do Arranjo Produtivo Local de Vestuário do Distrito Federal e seu entorno; (b) identificar os estilos de gerenciamento percebidos pelos empregados pertencentes às empresas do APL de Vestuário do Distrito Federal e seu entorno; (c) investigar a relação existente entre valores organizacionais e estilos de gerenciamento.

\section{Método}

\section{Participantes}

A amostra se constituiu de 355 empregados de $30 \mathrm{em}$ presas pertencentes ao Arranjo Produtivo Local de Vestuário, localizadas no Distrito Federal e seu entorno. De acordo com os dados obtidos, $84,8 \%$ da amostra é composta por mulheres; a idade média dos empregados é de 34,9 anos ( $\mathrm{DP}=10,3)$;
$48,7 \%$ possuem até o primeiro grau completo, sendo que, desses, $35,5 \%$ têm apenas o $1^{\circ}$ grau incompleto. O tempo médio de vínculo com as empresas é de três anos $(\mathrm{DP}=3,8)$, caracterizando uma amostra com $69,3 \%$ de empregados com até três anos na organização, sendo que $28,7 \%$ têm menos de um ano de vínculo com a empresa.

\section{Instrumentos}

Para o levantamento da percepção dos valores organizacionais predominantes nas empresas, foi aplicado o Inventário de Perfis de Valores Organizacionais - IPVO, de Oliveira e Tamayo (2004), com 48 itens, utilizando-se uma escala de seis pontos ( 1 - não se parece em nada com a minha empresa a 6 - é muito parecida com a minha empresa). Os respondentes deveriam avaliar o quanto as empresas descritas se pareciam com a sua, resultando em oito fatores: Realização, Conformidade, Domínio, Bem-estar dos empregados, Tradição, Prestígio organizacional, Autonomia e Preocupação com a coletividade.

A percepção do estilo de gerenciamento praticado nas empresas foi avaliada através da Escala de Avaliação do Estilo Gerencial - EAEG proposta por Melo (2001). O instrumento, com 19 itens, contém uma escala de cinco pontos (1 - nunca age assim a 5 - sempre age assim) que resulta em três fatores: Relacionamento, Tarefa e Situação.

\section{Coleta dos dados}

Os instrumentos, ministrados nas próprias empresas pesquisadas, foram apresentados em um único caderno de seis páginas, sendo a primeira parte referente aos valores organizacionais e a segunda aos estilos de gerenciamento, além de uma página de rosto com os dados demográficos. A aplicação dos questionários foi feita por meio de entrevistas individuais e em grupos de até dez participantes, que duravam, em média, 30 minutos nas duas modalidades de coleta de dados.

Utilizando-se de uma forma específica de coleta de dados para pessoas com baixa escolaridade (Borges \& Pinheiro, 2002). A cada participante foi entregue uma caixa subdividida em compartimentos, nos quais os cartões, em forma de quadrado, estavam ordenados segundo o tamanho. A parte da frente da caixa continha seis compartimentos (representando uma escala de seis pontos), com os cartões utilizados para responder ao instrumento de valores organizacionais, e no seu verso estavam os cinco compartimentos (representando uma escala de cinco pontos) para os cartões a serem utilizados para as respostas às questões do instrumento de estilos de gerenciamento. A graduação das escalas era representada pelos tamanhos crescentes dos cartões.

Os respondentes indicavam suas respostas para cada um dos itens dos questionários lidos pelo(a) aplicador(a), escolhendo um dos cartões e colocando-o no envelope devidamente numerado com o número da questão correspondente. Esse envelope era, então, depositado em um outro envelope maior, que reunia todos os envelopes pequenos de um mesmo participante, sem identificação. 
Para o questionário sobre valores organizacionais, por exemplo, o respondente escolhia o quadrado maior quando sua empresa era muito parecida com a empresa descrita e o menor quadrado quando a empresa descrita não se parecia em nada com a sua empresa, ou, ainda, um dos cartões do meio quando a empresa descrita se parecia "mais ou menos" com aquela em que ele trabalhava. Quando do levantamento do estilo de gerenciamento percebido, utilizou-se o mesmo procedimento. Quando a descrição da maneira de se comportar do gerente era semelhante à do seu chefe imediato, $\mathrm{o}$ respondente indicava o cartão maior (5 - sempre age assim). Quando era totalmente diferente, escolhia o menor cartão (1 - nunca age assim), ou escolhia um dos intermediários quando a escolha não recaía nos extremos da escala. Antes do início da leitura das questões, os aplicadores se certificavam de que os sujeitos tinham compreendido perfeitamente a escala apresentada, esclarecendo todas as dúvidas.

\section{Análise dos dados}

Preliminarmente, procedeu-se à análise exploratória dos dados, quando foram analisados a distribuição e seus pressupostos de normalidade, observando os níveis de assimetria e curtose, bem como os casos omissos e extremos. Conforme recomendações de Tabachinick e Fidell (2001), os casos omissos foram substituídos pela média das variáveis dos demais indivíduos, uma vez que se tratava de poucas ocorrências, $1,7 \%$ no pior caso. Os outliers univariados e multivariados foram identificados por meio de histogramas de frequência e cálculo da distância de Mahalanobis, respectivamente. Essa análise indicou a presença de outliers multivariados (Mahalanobis > 29,588), porém, decidiu-se pela não-eliminação desses sujeitos, tendo em vista que, assim procedendo, uma das empresas ficaria com apenas um empregado, além do fato da eliminação não ter modificado os resultados obtidos.

Embora tenham sido utilizadas duas metodologias na coleta dos dados (entrevista individual e grupal), decidiu-se pelo tratamento conjunto de ambas. A decisão foi tomada após os resultados do Test T, encontrados mediante a seleção aleatória, por meio do SPSS, de três amostras, com 95 sujeitos cada, retiradas do grupo de empresas em que foi utilizada a coleta de dados por meio de entrevista individual, ou seja, do grupo com maior número de sujeitos. Os valores organizacionais e os estilos de gerenciamento mais presentes nas organizações nessas três amostras foram iguais àqueles das empresas onde a coleta se deu pela metodologia grupal, formando também uma amostra de 95 respondentes. Portanto, conclui-se que o fato de terem sido utilizadas duas metodologias na coleta dos dados não interferiu nos resultados obtidos.

\section{Resultados}

Utilizou-se a média dos valores atribuídos pelos empregados em cada um dos fatores, por empresa, para identificar os valores organizacionais e os estilos de gerenciamento mais percebidos. Procedeu-se também ao cálculo da ANOVA para verificar a significância das diferenças encontradas entre as empresas (Tabelas 1 e 2).

Tabela 1

Resultado da ANOVA para Valores Organizacionais

\begin{tabular}{lcccrc}
\hline Valores Organizacionais & M & DP & df & \multicolumn{1}{c}{ F } & Sig. \\
\hline Realização & 5,01 & 0,99 & 29 & 7,79 & 0,00 \\
Conformidade & 5,05 & 0,89 & 29 & 12,29 & 0,00 \\
Domínio & 5,35 & 0,69 & 29 & 6,95 & 0,00 \\
Bem-estar & 3,00 & 1,45 & 29 & 11,71 & 0,00 \\
Tradição & 4,27 & 1,04 & 29 & 4,44 & 0,00 \\
Prestígio & 5,22 & 0,83 & 29 & 6,62 & 0,00 \\
Autonomia & 4,67 & 1,16 & 29 & 10,75 & 0,00 \\
Coletividade & 4,79 & 1,13 & 29 & 13,10 & 0,00 \\
\hline
\end{tabular}

Tabela 2

Resultado da ANOVA para Estilos de Gerenciamento

\begin{tabular}{lccccc}
\hline $\begin{array}{c}\text { Estilos de } \\
\text { Gerenciamento }\end{array}$ & M & DP & df & F & Sig. \\
\hline Relacionamento & 3,70 & 0,98 & 29 & 6,32 & 0,00 \\
Tarefa & 4,19 & 0,80 & 29 & 3,61 & 0,00 \\
Situação & 4,03 & 0,94 & 29 & 4,23 & 0,00 \\
\hline
\end{tabular}

Esses cálculos indicaram o valor organizacional Domínio como o mais presente nas 30 organizações, na percepção de seus empregados, representando $60 \%$ das empresas pesquisadas. Em seguida aparecem como valores mais fortes Conformidade e Prestígio organizacional, cada um em quatro empresas, Realização em duas empresas e Preocupação com a coletividade apenas em uma empresa. Uma das empresas da amostra apresentou dois valores organizacionais, concomitantemente: Conformidade e Domínio. Os valores organizacionais Bem-estar dos empregados, Autonomia e Tradição são os menos percebidos pelos empregados das empresas pesquisadas. Bem-estar apresenta as mais baixas médias da amostra e o maior desvio-padrão.

Apesar desses resultados, na quase totalidade da amostra pode-se observar que as médias dos valores organizacionais mais percebidos em cada uma das empresas situam-se nos pontos 4 (é mais ou menos parecida com minha empresa) e 5 (é parecida com minha empresa) da escala. Portanto, apesar de ter havido uma predominância de um valor organizacional, quase todos os outros valores estão acima da média teórica.

Os resultados das análises de estilo de gerenciamento indicaram o estilo Tarefa como o mais presente nas empresas. Tarefa esteve presente em 18 das 30 organizações, seguida de Situação, em dez empresas, e Relacionamento, em duas organizações.

Contudo, apesar do destaque para o estilo gerencial Tarefa, observa-se que quase todos os demais estilos 
apresentaram resultados acima da média, ou seja, nos pontos 3 (ocasionalmente age assim) e 4 (frequentemente age assim) da escala. Exceção feita apenas a cinco empresas, que tiveram médias abaixo do ponto 3 da escala.

Para atingir o terceiro objetivo do estudo, foi realizada análise de regressão linear hierárquica visando verificar o grau de contribuição da variável antecedente de estilo de gerenciamento (valores organizacionais) na explicação da variância da variável dependente.

Para o cálculo da regressão linear hierárquica, foram colocadas no primeiro bloco as variáveis de controle (sexo, idade, tempo na organização e instrução) e no segundo bloco todos os valores organizacionais, tendo como variável dependente cada um dos estilos de gerenciamento. A Tabela 3 resume o resultado encontrado para os três estilos de gerenciamento.

Tabela 3

Resultados da análise de regressão entre Estilo de Gerenciamento, Valores Organizacionais e Variáveis de Controle

\begin{tabular}{llccccccc}
\hline \multirow{2}{*}{ Estilos de Gerenciamento } & Valores Organizacionais & \multicolumn{2}{c}{$\begin{array}{c}\text { Coeficientes não } \\
\text { padronizados }\end{array}$} & \multicolumn{2}{c}{$\begin{array}{c}\text { Coeficientes } \\
\text { padronizados }\end{array}$} \\
\cline { 3 - 8 } & & $\mathbf{B}$ & $\begin{array}{c}\text { Erro } \\
\text { padrão }\end{array}$ & Beta & t & Sig. & $\mathbf{R}^{\mathbf{2}}$ \\
\hline \multirow{2}{*}{ Relacionamento } & Autonomia & 0,24 & 0,08 & 0,28 & 3,13 & 0,002 & 0,325 \\
& Bem-estar & 0,13 & 0,04 & 0,19 & 3,11 & 0,002 & \\
Tarefa & Conformidade & 0,25 & 0,07 & 0,27 & 3,80 & 0,000 & 0,307 \\
Situação & Autonomia & 0,23 & 0,08 & 0,28 & 2,84 & 0,005 & 0,182 \\
\hline
\end{tabular}

$\mathrm{Na}$ análise dos pesos únicos, os valores organizacionais Autonomia $(\mathrm{B}=0,28)$ e Bem-estar $(\mathrm{B}=0,19)$ aparecem como os melhores preditores individuais para o estilo de gerenciamento Relacionamento, os dois com associação direta, sendo que o efeito mais forte está em Autonomia. O valor organizacional Conformidade $(\mathrm{B}=0,27)$ aparece como único preditor do estilo de gerenciamento Tarefa. $\mathrm{O}$ estilo de gerenciamento Situação tem como melhor preditor o valor organizacional Autonomia $(\mathrm{B}=0,28)$. As variáveis de controle não são preditores dos estilos de gerenciamento.

\section{Discussão}

\section{Relações entre valores organizacionais e estilos de gerenciamento}

Poder-se-ia supor que as ações estratégicas adotadas pelo SEBRAE/DF para formar e fortificar o Arranjo Produtivo como uma unidade de negócio, seriam traduzidas em percepções comuns dos valores organizacionais e dos estilos de gerenciamento.

Apesar disso, cada uma das empresas que fazem parte do APL pesquisado apresentou valores e estilos de gerenciamento específicos, peculiares à realidade de cada uma e decorrentes das soluções dadas aos problemas específicos enfrentados no mundo dos negócios. Vale ressaltar, contudo, que uma percentagem significativa das empresas (60\%) apresentou o mesmo valor organizacional Domínio e o mesmo estilo de gerenciamento Tarefa.

Esses resultados estão de acordo com a Teoria dos valores organizacionais, que especifica o aspecto hierárquico dos valores, representando o quanto os empregados preferem e investem esforços em determinados comportamentos, metas ou estratégias. $\mathrm{O}$ aspecto hierárquico, ou seja, o grau de importância que os membros organizacionais atribuem aos valores, diferencia uma empresa de outra, ainda que sejam pertencentes a um mesmo segmento e estejam submetidas a um mesmo cenário de negócios. Logo, também a predominância do estilo de gerenciamento Tarefa traduz a opção por uma forma de gestão coerente ao valor perseguido pelas empresas.

Além disso, os valores organizacionais são formados, na sua grande maioria, pelos valores pessoais, aqueles que os empregados trazem quando ingressam nas empresas. Portanto, os valores das empresas pesquisadas expressam tanto os interesses e desejos dos empregados como da organização, que são representados pelas metas que motivam suas ações.

Como explicitado acima, em $60 \%$ das empresas pesquisadas (18 empresas) o valor Domínio é percebido por seus empregados como o mais presente. Esse resultado expressa a ênfase dessas micro e pequenas organizações em se colocarem no mundo dos negócios, altamente competitivo e seletivo. Essas empresas apresentam como meta a busca de status, prestígio social e domínio sobre pessoas e recursos, pois precisam dominar o mercado, impondo seus produtos e sua imagem.

Observa-se nos resultados um grupo de valores organizacionais - Domínio, Prestígio organizacional e Realização -, que se destacam como aqueles mais percebidos pelos empregados, apenas diferindo na hierarquia que aparecem em cada empresa. Assim, as organizações pertencentes à amostra estão sendo fortemente guiadas por valores relacionados ao poder e ao sucesso, cuja meta central é a obtenção de status, prestígio e a busca de posição dominante no mercado.

Esses resultados retratam com bastante coerência a realidade da amostra. O segmento de vestuário no Distrito Federal e seu entorno é bastante novo, encontrando-se ainda em fase de estruturação. De acordo com o Diagnóstico Preliminar do Pólo Brasília, realizado no ano de 2004 pelo SEBRAE Nacional e pelo Sindicato das Indústrias do Vestuário do Distrito Federal - SINDIVEST, através do Instituto 
Euvaldo Lodi - IEL, diversos são os fatores que dificultam o desempenho dessas empresas, tais como alta carga tributária, acesso às linhas de crédito, demanda insuficiente e pouca capacitação dos empregados, dentre outros. Portanto, como salientado por Tamayo e Gondim (1996), os resultados expressam as metas e os padrões de comportamentos que essas empresas têm priorizado no enfrentamento de seus problemas.

$\mathrm{Na}$ amostra pesquisada, o valor percebido com menor força é Bem-estar dos empregados, demonstrando a pouca preocupação das organizações em proporcionar aos seus membros prazer e satisfação. Frente ao cenário de negócios enfrentado por essas micro e pequenas empresas, provavelmente existe, neste momento em que elas lutam para se colocarem e permanecerem no mundo empresarial, uma grande demanda para as questões consideradas de primordial importância para a sobrevivência da organização, sobrando pouco ou nenhum espaço para efetivação de ações voltadas ao bem-estar dos empregados.

Com relação aos estilos de gerenciamento, na percepção dos empregados de 18 empresas (60\% da amostra), Tarefa é o estilo de gerenciamento mais forte nas organizações. Nessas empresas, o foco está no trabalho e a orientação é para a produção.

Os gerentes estão preocupados em estruturar o seu papel e o de seus subordinados, designando os empregados para as tarefas, descrevendo as tarefas dos cargos, definindo padrões de desempenho, entre outras atividades de controle, supervisão e fiscalização. Nessas organizações, predominam a autocracia e a falta de autonomia e de participação dos empregados nas decisões da empresa. Na melhor das hipóteses, o empregado é chamado para legitimar as decisões já tomadas pela chefia.

Observa-se na realidade das empresas pertencentes ao Arranjo Produtivo Local de Vestuário que o programa de produção tem sido bastante rígido para atender às demandas do mercado. São estabelecidos prazos e metas que não podem ser alterados, em função da necessidade de buscar a fidelidade dos clientes e ganhar ou garantir uma posição no mercado. Portanto, nada mais lógico ser o estilo de gerenciamento Tarefa o mais percebido pelos empregados.

Acrescenta-se, ainda, o momento atual dessas micro e pequenas empresas que precisam conquistar o mercado e impor seus produtos e sua imagem. Essa situação é retratada quando se observa que 12 das 18 empresas em que seus empregados percebem Tarefa como o estilo de gerenciamento mais forte têm Domínio como o valor organizacional predominante.

O estilo de gerenciamento Relacionamento foi o menos percebido nas organizações do APL de Vestuário. Esse resultado parece apresentar uma ligação com o valor organizacional Bem-estar dos empregados, que foi também o de menor frequência. Com base nas definições de Melo (2001), as empresas pesquisadas não enfatizam as relações interpessoais e seus gerentes estão muito pouco voltados para as questões ligadas à satisfação dos seus subordinados. Nessa empresas, apesar de existirem poucos níveis hierárquicos, em decorrência de seu tamanho, as decisões são tomadas pelas chefias e comunicadas aos subordinados. A comunicação entre chefia e subordinados é, portanto, bastante dificultada, possivelmente criando um clima de desconfiança no grupo.

Além de identificar os valores organizacionais e os estilos de gerenciamento das empresas pertencentes ao Arranjo Produtivo Local de Vestuário, foi investigada a relação existente entre esses dois construtos. Os resultados demonstram que o estilo de gerenciamento voltado para o relacionamento é predito pelos valores organizacionais Autonomia e Bemestar dos empregados. Segundo definição de Tamayo (1996), Autonomia tem como objetivo o aperfeiçoamento constante do empregado e da organização. Nessas empresas o trabalho criativo é incentivado, assim como a busca de novas experiências e desafios. Nos itens que formam o fator Bem-estar dos empregados, o foco é ter empregados satisfeitos, sentindo-se realizados profissionalmente e com qualidade de vida no trabalho. Pode-se observar, portanto, que os dois valores organizacionais (Autonomia e Bem-estar dos empregados) estão a serviço, prioritariamente, dos interesses dos indivíduos, assim como o estilo de gerenciamento Relacionamento está focado no respeito às ideias dos empregados, envolvendo-os na vida organizacional.

O estilo de gerenciamento voltado para a Tarefa apresenta como único preditor o valor organizacional Conformidade. Como salienta Soto (2002), a liderança diretiva ou orientada para a Tarefa tem prioridade na produção, sendo ideal para as organizações que precisam cumprir metas muito rígidas. É esperado, portanto, que nessas empresas o valor de Conformidade seja o predominante, com foco no controle do ambiente organizacional por meio da definição de limites e regras e da manutenção de modelos de comportamento que possam assegurar o alcance de suas metas e objetivos. Tanto o valor Conformidade quanto o estilo de gerenciamento Tarefa servem a interesses, preponderantemente, da organização.

Por último, o valor organizacional Autonomia surge como preditor do estilo de gerenciamento Situação. Empresas com valor de Autonomia têm como foco o crescimento profissional, a abertura para mudança, a criatividade, a iniciativa e a busca de novas experiências e desafios (Tamayo, 1996). Assim, essas organizações precisam agregar e considerar outras informações e conhecimentos no contexto do trabalho para que possam atuar na busca do desenvolvimento dos empregados e da organização. Para tanto, precisam adotar formas de gerenciamento que considerem as variáveis moderadoras na relação entre liderança e eficácia grupal, ou seja, as variáveis de contexto ou situacionais. Como salientado na abordagem de liderança situacional de Hersey e Blanchard (1974), é necessário que o gerente considere o nível de maturidade grupal, que é a combinação da competência e da motivação do empregado para o desempenho de determinada tarefa. 
Os resultados obtidos neste estudo reforçam o quanto os valores organizacionais percebidos pelos empregados expressam as crenças sobre o que é desejável ou não para a organização, servindo de padrões de comportamentos a serem seguidos no ambiente organizacional. Expressam, por meio da predominância do valor organizacional Domínio, o quanto os empregados pertencentes às empresas pesquisadas preferem e investem esforço na busca de status, prestígio social e domínio sobre pessoas e recursos.

Evidenciam também os resultados a importância da liderança na implementação, modificação e manutenção da cultura organizacional e, especificamente, dos valores das empresas. Essa importância da liderança fica claramente evidenciada na medida em que o estilo de gerenciamento Tarefa, o mais presente nas organizações, na percepção de seus empregados, caracteriza-se pela ênfase na produção, com metas rigorosamente definidas e controle das pessoas e dos recursos. Esse estilo de gerenciamento está focado em aspectos de fundamental importância para empresas que precisam dominar o mercado e, possivelmente, afetará diretamente os resultados das organizações pertencentes ao Arranjo Produtivo Local de Vestuário do Distrito Federal e seu entorno.

Dentre os aspectos que podem ter influenciado os resultados da pesquisa e que deverão ser considerados em pesquisas futuras, destacamos: (a) a adequada compreensão das instruções e dos instrumentos utilizados frente às características da amostra constituída de pessoas de baixa escolaridade, pertencentes a classes sociais menos privilegiadas. Em futuras pesquisas, faz-se necessário realizar validação semântica dos questionários em outras amostras para possível aprimoramento do instrumento; (b) grau de leniência e de desejabilidade presente na amostra, expressos pela tendência dos respondentes a utilizarem os maiores valores da escala, possivelmente decorrente do nível de desconfiança em relação ao destino e à utilização dos resultados da pesquisa. Para minimizar os efeitos decorrentes desse tipo de situação, poder-se-ia realizar a coleta de dados em local considerado neutro, fora da empresa e longe da presença de suas chefias, misturando empregados de diversas organizações; (c) a utilização apenas de método quantitativo pode ter limitado a compreensão da realidade organizacional. Talvez a análise qualitativa constitua uma forma complementar de tratamento dos dados, que possibilite melhor compreensão dos fenômenos estudados.

$\mathrm{Na}$ realização deste estudo, alguns desafios foram enfrentados e outros permanecem, tal como a necessidade de estudos longitudinais, para que as percepções dos empregados possam ser investigadas após a melhor estruturação e desenvolvimento das empresas pertencentes ao Arranjo Produtivo Local de Vestuário, enriquecendo, assim, a compreensão desse segmento empresarial e dessa população ainda tão pouco estudados pela Psicologia Social e do Trabalho, como salientado na introdução deste estudo.
Um dos desafios enfrentados foi o tamanho das empresas que fizeram parte desse estudo. O número reduzido de empregados (algumas empresas com três, quatro ou seis empregados e outras com 22, 33 ou 62 empregados) dificultou análises estatísticas mais aprimoradas. A título de exemplo, embora o teste de significância (ANOVA) tenha dado bons resultados, pode ser questionado por terem sido feitas comparações entre organizações com quantidades tão díspares de empregados. Pode-se, também, questionar se podemos falar de valor organizacional em empresas com apenas três empregados.

Entretanto, essa é a realidade do enorme contingente de pequenos empreendimentos existentes no Brasil. De acordo com dados do Boletim Estatístico de Micro e Pequenas Empresas (SEBRAE, 2005), o conjunto das micro e pequenas empresas em atividade respondeu, em 2003, por 99,2\% do número total de empresas formais, contra $0,3 \%$ das grandes empresas, por $57,0 \%$ dos empregos totais e por $26,0 \%$ da massa salarial.

Outro desafio que este estudo enfrentou foi o de estudar uma população caracterizada por baixos níveis de instrução. Como apontado por Borges e Pinheiro (2002), é escassa a produção de pesquisa científica na área da Psicologia Social e do Trabalho com esse segmento da população. Assim, constatamos a necessidade de serem aprimoradas técnicas de coleta de dados e de serem desenvolvidos instrumentos mais sensíveis, para que os resultados das pesquisas científicas possam ter a devida relevância social, considerando que o Brasil tem um enorme contingente de pessoas com baixa escolaridade. Os resultados do Censo Demográfico de 2000 indicam um percentual de $30,6 \%$ de pessoas acima de 25 anos que possuem apenas o ensino fundamental incompleto (Instituto Brasileiro de Geografia e Estatística [IBGE], 2000).

Os resultados deste estudo, frente às características da amostra estudada, trazem uma contribuição significativa na produção de conhecimentos para a Psicologia Social e do Trabalho. É importante, pois, ressaltar seu aspecto pioneiro e sua relevância na medida em que se aventura a estudar e a desvendar a realidade das micro e pequenas organizações, bem como as percepções de pessoas com baixo nível de escolaridade. Normalmente, a Psicologia Social e do Trabalho tem cuidado pouco ou quase nada dessa população, principalmente no Distrito Federal, onde as pesquisas, em sua maioria, têm se concentrado em organizações públicas.

Espera-se que os resultados deste estudo possam subsidiar as ações das instituições estatais e não-estatais na definição e operacionalização de ações junto a seus clientes, com características semelhantes às da amostra pesquisada, bem como fortalecer a parceria entre as organizações e a universidade.

Que outros pesquisadores possam se interessar em estudar as organizações de pequeno porte e as populações de baixa escolaridade, produzindo conhecimentos que possam ser generalizados para a realidade brasileira. 


\section{Conclusão}

Os dois objetivos deste estudo - identificar os valores organizacionais e os estilos de gerenciamento e investigar a relação entre esses dois construtos - foram alcançados. A presente pesquisa ofereceu contribuições para questões presentes no campo de valores organizacionais e estilos de gerenciamento, bem como no contexto das organizações de pequeno porte.

Os resultados demonstram e reforçam a importância dos valores organizacionais no contexto das empresas como elemento orientador dos esforços a serem empreendidos pelos membros organizacionais. Além disso, fica clara a vinculação dos valores com as necessidades do contexto organizacional e as demandas externas, pontuando o rumo a ser seguido para alcance de seus objetivos.

Cada realidade empresarial demanda esforços específicos em metas, comportamentos e estratégias, que vão definir os valores da organização, bem como o estilo de gerenciamento adequado às suas necessidades. $\mathrm{O}$ estilo de gerenciamento representa a forma de gestão coerente com o valor perseguido pela organização. Assim, valores de Autonomia e Bem-estar despontaram nesta pesquisa como preditores do estilo de funcionamento Relacionamento, pois estão focados nos interesses dos indivíduos, na busca da participação dos membros organizacionais, envolvendo-os nas tomadas de decisões. Por outro lado, o valor organizacional Conformidade é preditor do estilo de gerenciamento Tarefa, pois os dois estão vinculados, prioritariamente, aos interesses da organização.

Os valores organizacionais e os estilos de gerenciamento percebidos pelas pessoas vinculadas às empresas participantes desta pesquisa retratam, com bastante coerência, a realidade da amostra formada pelas: micro e pequenas organizações, em fase de estruturação, que buscam poder, sucesso, prestígio e uma posição dominante no mercado e que adotam um estilo de gerenciamento voltado para o controle e para a supervisão direta da produção, com o objetivo de atender às demandas do mercado.

Em termos práticos, a verificação das condições e características organizacionais que influenciam na maneira com que as empresas enfrentam suas necessidades básicas, definindo metas e comportamentos desejáveis que orientem a vida da empresa (valores organizacionais) e o estilo de gerenciamento, pode contribuir para uma melhor compreensão da realidade das organizações, bem como para o planejamento de intervenções nos ambientes de trabalho.

Importantes habilidades são requeridas do líder para que se possam concretizar as mudanças necessárias nas diferentes fases da vida organizacional. Russo, Ruiz e Cunha (2005), ao analisarem o papel da liderança como um fator crítico de sucesso, afirmam que, apesar dos resultados continuarem a ser o foco mais importante de qualquer negócio, é preciso buscar um estilo de gerenciamento que concilie os resultados com uma eficaz gestão de pessoas, possibilitando, por um lado, autonomia e realização profissional e pessoal e, por outro, a equivalente responsabilidade e compromisso com a organização.

\section{Referências}

Bass, B. M. (1990). Bass \& stogdill's handbook of leadership: Theory, research, and managerial applications. New York: The Free Press.

Borges, L. O., \& Pinheiro, J. Q. (2002). Estratégias de coleta de dados com trabalhadores de baixa escolaridade. Estudos em Psicologia, 7(n. esp), 53-63.

Instituto Brasileiro de Geografia e Estatística. (2000). Censo demográfico 2000. Brasília: IBGE.

Cocco, G., Urani, A., Galvão, A. P., \& Silva, M. P. (2002). Desenvolvimento local e espaço público na terceira Itália: Questões para a realidade brasileira. In U. André, C. Giuseppe, \& P. G. Alexander (Orgs.), Empresários e empregos nos novos territórios produtivos: O caso da terceira Itália (2a ed., pp. 13- 32). Rio de Janeiro: DP\& A.

Dorfman, P. (1996). International and cross-cultural leadership. In B. J. Punnett \& O. Shenkar (Eds.), Handbook for international management research (pp. 267-349). Cambrigde, MA: Blackwell.

Hersey, P., \& Blanchard, K. H. (1974). Psicologia para administradores de empresas. Rio de Janeiro: EPU.

Kabanof, B., \& Daly, J. (2002). Espoused values of organizations. Australian Journal of Management, $27(\mathrm{n}$. esp.), 89-104.

Koslowsky, M., \& Stashevsky, S. (2005). Organizational values and social power. International Journal of Manpower, 26(1), 23-34.

Liu, W., Lepak, D. P., Takeuchi, R., \& Sims Jr., H. P. (2003). Matching leadership styles with employment modes: Strategic human resource management perspective. Human Resource Management Review, 13, 127-152.

Melo, E. A. de A. (2001). Comprometimento organizacional, estilos gerenciais e poder organizacional: Um estudo relacional. Dissertação de mestrado não-publicada, Instituto de Psicologia, Universidade de Brasília.

Oliveira, A. F., \& Tamayo, A. (2004). Inventário de perfis de valores organizacionais. Revista de Administração da USP, 39, 129-140.

Russo, R. de F. S. M., Ruiz, J. M., \& Cunha, R. P. da (2005). Liderança e influências nas fases da gestão de projetos. Revista Produção, 15(3), 362-375.

Schwartz, S. H. (1999). A theory of cultural values and some implications for work. Applied Psychology: An International Review, 48, 23-47.

Serviço Brasileiro de Apoio às Micro e Pequenas Empresas. (2005). Boletim Estatístico de Micro e Pequenas Empresas (Observatório SEBRAE).

Serviço Brasileiro de Apoio às Micro e Pequenas Empresas. Sindicato das Indústrias do Vestuário do Distrito Federal. (2004). Diagnóstico preliminar do Pólo Brasília. 
Silva, L. S. (2007). Valores organizacionais e valores humanos como fatores de impacto no bem-estar ocupacional. Dissertação de Mestrado não-publicada, Universidade Presbiteriana Mackenzie, São Paulo.

Smith, P. B., Peterson, M. F., Akande, D., Callan, V., Cho, N. G., Jesuino, J., D’Amorim, M. A., Koopman, P., Leung, K., Mortazawi, S., Munene, J., Radford, M., Ropo, A., Savage, G., \& Viedge, C. (1994). Organizational event management in fourteen countries: A comparison with Hofstede's dimensions. In A. M. Bouvy, F. Van Der Vijver, P. Schmitz, \& P. Boski (Orgs.), Journeys into cross-cultural psychology (pp. 364-373). Amsterdam: Swets \& Zeitlinger.

Soto, E. (2002). Comportamento organizacional. São Paulo: Pioneira Thomson Learning.

Tabachinick, B. G., \& Fidell, L. S. (2001). Using multivariate statistics (4a ed.). New York: Allyn \& Bacon.

Tamayo, A. (1996). Valores organizacionais. In A. Tamayo, J. E. Borges-Andrade, \& W. Codo (Orgs.), Trabalho, organizações e cultura (pp. 175-493). São Paulo: Cooperativa de Autores Associados.

Tamayo, A., \& Gondim, M. G. C. (1996). Escala de valores organizacionais. Revista de Administração da USP, 31(2), 62-72.

Tamayo, A., \& Porto, J. B. (Orgs.). (2005). Valores $e$ comportamentos nas organizações. Petrópolis/RJ: Editora Vozes.

Termo de Referência para Atuação do Sistema SEBRAE em Arranjos Produtivos Locais. (2003). São Paulo: SEBRAE.

Torres, C. V. (1999). Leadership style norms among americans and brazilians: Assessing differences using Jackson's Return Potential Model. Tese de Doutorado não-publicada, Faculty of the California School of Professional Psychology, San Diego.

Eliana Elisabete Moreira Gosendo é Professora Titular do Curso de Mestrado em Administração do Centro Universitário UNIEURO.

Claudio Vaz Torres é Professor Titular do Instituto de Psicologia da Universidade de Brasília.

Recebido: $26 / 08 / 2008$

$1^{a}$ revisão: 19/05/2009

Aceite final: 11/06/2009 